\title{
Conversational Agents for the Elderly, the Guardian Platform
}

\author{
Andressa Ferreira \\ State University Of Ceara \\ andressa.magda@aluno.uece.br \\ Mariela Cortés \\ State University Of Ceara \\ mariela@larces.uece.br
}

\author{
Adson Damasceno \\ State University Of Ceara \\ adson.damasceno@aluno.uece.br \\ Fran Oliveira \\ State University Of Ceara \\ fran.oliveira@uece.br
}

\begin{abstract}
With increasing of life expectancy innovative solutions that ensure well-being of the seniors become most needed. In this context, in order to deny the main difficulties reported by the senior public with the use of mobile devices, we propose a technology entirely based on voice interactions and we name this project of Guardian. The essence of the project is to provide, through a mobile application, a platform with a set of intelligent agents focused on the well-being of the older adults. In this work the mains objectives to analyze and evaluate the usability of the Guardian and the cultural impacts of the technology. For the data collection, video recordings were used, a questionnaire that identifies the socio-technological profile of the research participants and the system usability scale (SUS).
\end{abstract}

\section{KEYWORDS}

Elderly, Voice interaction, Conversational agent, Natural language processing, Mobile application

\section{INTRODUCTION}

Following a worldwide trend, in Brazil, demographic data has been showing an increase in the proportion of the number of older adults over the total population. Projections by the Brazilian Institute of Geography and Statistics (IBGE) estimate that, by 2060, one in four Brazilians will be over 65 years [1].

With increasing life expectancy, longevity has come to be seen not only as a gain, but also as a concern for society. According to Nahas [2], aging human population leads to an increase in the incidence of chronic-degenerative diseases, more common in old age. This leads to a growing contingent of people who, sooner or later, become dependent on others for even the simplest tasks, such as going to the bathroom or making a cell phone call.

This accelerated growth of the elderly population represents major challenges not only for families but also for society, mainly due to the decrease in the number of health professionals compared to the number of elderly people. Caregivers often complain of overload, depression, stress, and anxiety. They leave aside, frequently, the profession, the leisure activities and self-care, which can lead to impairments in the quality of life and care provided to the elderly [3-5].

In this context, the use of smart mobile assistants becomes a promising solution to alleviate the problem of a greater demand for care services for the elderly, contributing not only to helping the activities of caregivers and family members, but also in the recovery of the elderly independence. With this scenario, this work positions itself in a reality where there is a shortage of computational tools to promote the autonomy and the empowerment of the elderly. Empowerment for the elderly provides them with an expanded view of power, to know how to interact with society, and know how to handle and confront with their everyday situations. This empowerment can be offered to them through methods that can be developed in a particular or collective way stimulating their self-sufficiency. In addition, it is also known that an independent life reduces the cost to society of supporting people who have lost some autonomy [6].

Our project, Guardian, aims to provide a friendly technology, accessible and entirely based on voice interactions, aiming to provide and facilitate the use, for the elderly who don't have a caregiver or those who wish to live in a more autonomous way, a platform in which the same has access to diversified and interesting services, services directed from their personal care to their entertainment.

The Guardian technology consists of a set of conversational assistants focused on helping healthy aging and available in a single application embedded on a mobile device. Unlike Amazon's, Apple's and Google's general propose conversational plataforms, in our approach, there is only one application running on the equipment. With this sole propose, it is expected that problems associated with Discoverability - common when interacting with conversational agents [7] - to be lessened.

This multi-agent architecture was implemented using a variety of technologies, such as a Google tool called Dialogflow and Android Native. Our technology has the differential of providing more than care, provide a friend, an individual who is fully available and that gradually learns and creates an intimate relationship with its user. Our goal is a continuous adherence of technology in the daily life of the elderly who wish to live more autonomously of caregivers and family members or simply don't have access to such care.

It is worth mentioning that a search conducted in academic libraries for similar solutions didn't produce significant results. We look for mobile platforms of intelligent assistants targeted at the elderly public. We use the descriptors for the elderly, conversation assistants, mobile and synonyms of the same. This made us realize that this is an area still under-explored and motivated us to continue with the project.

However, given the innovative content of the proposal there are several questions to be explored. Thus, this present study was designed to address the following research questions: 1) Are personal assistants like Amazon's Alexa or Google's assistant offer any help for third world country seniors? 2) How does such population receive and interact with such technology? 3) Which culture related issues might arise from the introduction of the technology in their daily lives? 4) Which possible positive impacts can be fore- 
seen with the use of conversational assistants? 5) Which design guidelines can be drawn from this exploratory study? The purpose of the study reported in this article is to answer these questions by conducting a user evaluation through a usability test in the user's home (in-situ experiment).

This article is organized as follows: the next section describes some recent work that also investigates voice interfaces with the elderly public. Next, the accessibility features of our proposal are presented. In the next section, the architecture of our application is detailed. Then, we expose our methodology. After this, we discussed the results of quantitative and qualitative evaluations. Then we expose the threats to the validity of our work and finally the conclusions and the future work are presented.

\section{RELATED WORK}

To use the voice interfaces on the mobile device more effectively, we examined how other researchers applied voice technology with elderly user.

In the Sweet-Home project Portet et al. [8] evaluated the acceptability of voice interfaces by autonomous elderly people in a context of smart home. In this work an intelligent domestic environment was developed and studied in a laboratory simulating the real domestic environment (in-sitro / in-simu experiment) with eight elderly people, their families and caregivers. The authors sought to test the four important aspects of Smart Home Care: voice control, communication with the outside world, system interruption human activity and electronic agenda. In each of these aspects scenarios were developed in which the elderly were asked to interact with the environment and to answer questions related to this interaction. The results of the study showed that the elderly prefer voice interfaces over other interaction methods, such as typing or touch interfaces, but that they worried about their privacy and the potential decrease of activities caused by home automation.

In Reis et al. [9] the authors assess the main problems related to social relations among the elderly population, as well as the acceptance and introduction of intelligent assistants to stimulate such interaction. The results were promising. The elderly were very enthusiastic about the introduction of the assistants. It was noted that voice communication with electronic devices showed considerable utility to increase confidence and subsequently strengthen the social bonds of the elderly. Based on this research, an interaction model was developed to be carried out by the assistant and the elderly, in order to communicate to the elderly about the social events in progress of their relatives, friends and provide them with suggestions and engagement options.In [10] the possibility of using current commercial assistants (Google Assistant, Microsoft Cortana, Amazon's Alexa and Apple's Siri) was evaluated to implement this model. The four assistants were tried on top of five requirements: (1) user identification; (2) state of mind assessment; (3) current context, (4) personal information acquisition; and (5) a set of activity proposals. After evaluations it was realized that the Amazon assistant had the potential to fulfill most of the objectives of the proposed model.

Noh et al. [11] proposes a virtual interface that simplifies the interface of a smartphone for the elderly. The proposal displays menus according to the situation and user request through a virtual agent. Voice recognition technology is applied to receive information from the users and portable sensors are connected for receive gesture information. A preliminary study to evaluate the proposed method was performed with five elderly. Four of the five approved the method, while one didn't feel comfortable using the smartphone with the new interface.

In Cheng et al. [12] the authors aim to assist self-management for elderly patients with diabetes by proposing an application that uses the Google Home voice interface, by means of an artificial intelligence (conversational bot) implemented using the tool API.AI (current Dialogflow), and a Web interface for data visualization, because with google home the user has no way to view his information later. Google's home device has been chosen for its potential to negate the major difficulties that older people may face when handling complicated interfaces on small smartphone screens, since with Google Home, the interactions are by voice. After a test conducted with ten elderly users, with focus on the Google Home voice component, the general acceptance of them was noted. Most people attributed its high usability to its speaker functionality and natural conversation flow.

Pradhan [7] argues in his work that voice-controlled smart personal assistants such as Amazon's Echo Dot and Microsoft's Cortana seem to have greater potential to reach the elderly population. However, issues such as discoverability (ability to find the right application) and poor dialogs present themselves as barriers to accessibility. Another problem relates to mobility since as a rule, these new equipment are designed for home.

As discussed in the above works the use of voice interfaces has been shown to be well accepted by elderly users. However, most of the solutions currently found are restricted to closed environments, thus limiting user use.

\section{ACCESSIBILITY}

For the elderly, mobile apps are ineffective and even frustrating to use [12]. Despite its potential impact, several factors contribute to low adherence to mobile solutions among the elderly: 1) low visual acuity; 2) loss of memory and; 3 ) the decrease in manual dexterity are significant examples [13].

The process of aging of the human being is accompanied by a series of specific characteristics like stiffness in the joints, loss of memory and loss of visual quality. Therefore, the elderly need properly developed products so that they can develop their activities without difficulty. The digital exclusion of the seniors is caused by the lack of equipment developed especially for them, and with mobile devices is no different. Thus, accessibility is about removing barriers that somehow exclude some people from using a service.

Our work aims to deny the main difficulties encountered in the use of mobile devices by the elderly, such as tactile interactions. We focus not only on making it viable, but on simplifying the use of a mobile application for this public. In the prototype of our application all interactions are given by voice. We develop our agents so that they guide the seniors as the dialogue progresses, preventing them from feeling lost or fearful of squeezing something that might cause some system error. Making the application simple and easy to use. 
Slavík [14] argues that talking is the most natural way for communication and that audio interfaces are, therefore, a priori, highly usable for many types of people in many situations. Our technology focuses on the seniors, but can be used by many other public with or without limitations. Accessibility shouldn't only be related to the needs of people with disabilities, but to all people [15].

\section{GUARDIAN ARCHITECTURE MODEL}

With our proposal the user has, through a single Android Native application, access to a set of intelligent agents implemented in a Google tool called Dialogflow. The DialogFlow tool is an api.ai upgrade developed by Google. This tool allows the construction of conversation interfaces for bots, applications and devices [16]. In the DialogFlow platform environment, it is necessary to understand four very important concepts for the construction of conversation agents: intents, entities, contexts and fulfillments.

The intentions map user inputs to actions or responses to be executed/provided by the application. Each intention is associated with a set of training phrases, actions, responses, and contexts. When evaluating an input, the intent classifier may consider contextual information that helps you differentiate between similar inputs that should result in different actions/responses. Entities are used to identify specific items that the user refers to in their input. Once the user's intent has been sorted and the entities related to it have been identified, the server can perform actions specific to that intent, with its context and specific entities.

Each Intent can have fulfillment enabled which enables to pass information into a web service and get a result from it. When the Intent is triggered by a user's input, if the fulfillment is enabled, then a function will also trigger in the backend. Each Intent can have parameters for extracting information from user inputs, this are the entities used in the training phrases so far. Parameters can also be populated directly from the webhook or from other Intents using contexts and don't necessarily have to be part of the training phrases.

Our agents use these elements to provide helpful responses to users. When the user opens the Android application on their smartphone we send a signal programmatically to Dialogflow, so that we get a response consisting of the presentation of our initial agent, Lady Laura. This strategy was used for the agent to initiate the conversation with the user, point at which assistants like Google Assistant lose, because in them the user who initiates the conversation. After the application opens and our initial assistant starts the conversation it guides the user through the conversational flow, requesting information to get to know him better and provide contextualized information, for example, by providing the day and the month of the users birthday the Lady Laura maps the information and uses a fulfillment to search for the daily astrology forecast of the user. Another example is the exchange of personal information such as the name, when the user gives his name to the agent, it passes the information through the contexts, so that the information is not lost in the conversation flow.

We also implemented a change of agents. When created in Dialogflow, each agent receives a client access token that is responsible for its identification. We leave the reference for each agent dynamic in the Android source code, allowing multiple agents to be called

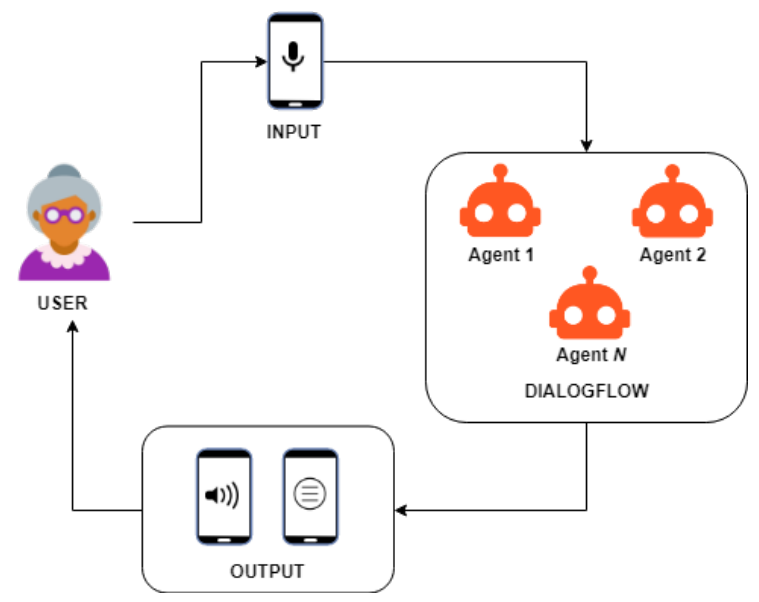

Figure 1: Simplified Guardian Architecture

one at a time. Thus, when the user changes the subject of their conversation with the agent, we change the key to that of another agent focused on the new topic addressed. For example, when the user wants to receive a revenue, we simulate a system outage to give the impression that one agent calls the other and then we automatically restart the Android application with the new agent initiating the conversation. In the case of culinary recipe, the new agent comes up with a revenue sought through another fulfillment and provides it to the user. The user can still continue with the current agent or choose to speak to the initial agent who initiated the conversation. In our prototype we only work with two agents for a viability test, but this logic fits well for the creation of a set of agents implemented in Dialogflow and called in the Android application. Figure 1 illustrates our agent architecture in a simplified way.

\subsection{THE CONVERSATIONAL AGENTS}

Two conversational agents were developed in order to validate our proposal: Lady Laura and Ana Maria. We detail both below.

Lady Laura represents a caring mother, a person who is present to give full attention and to pull a small talk with the older adult to pass the time when the same is feeling alone. Its name was chosen purposely to send memories to an old Brazilian popular music, popular among the elderly, of the singer Roberto Carlos of name Lady Laura, in tribute to the mother of the singer. The direction of her conversation takes place in the field of Astrology. She informs to the user of his / her sign in the Chinese horoscope after obtaining his / her birth year and also provides daily forecasts of astrology, given the day and the month of his birthday. We incorporated this theme into Lady Laura's conversation after the result of a brief survey with the seniors of the popularity of this topic among users of this age group.

The Ana Maria is our culinary expert, her name was also purposely provided to send memories to a culinary program very popular in Brazil and appreciated by viewers of the most different age groups. The idea of providing healthy recipes to the seniors through a conversation agent came from the intention of attracting 
the user to lead healthier eating habits through a balanced diet. In addition we intended to get them to cook and thus to become more distracted during their day to day eliminating feelings of idleness reported by many in this age group.

Rossel [17] affirms that loneliness is one of the most frequent complaints among the older adult population. With this in mind we seek to convey in our agents feelings of companionship and affection. Our proposal don't focus only in to make feasible the use of a mobile application by the seniors or simplify your routine activities, our main purpose is to provide a friend, a companion that is available all the time for its user.

\subsection{THE APPLICATION}

In order to use the application, the following process must be performed: on the mobile device running only the Guardian service, for testing purposes a smartphone was used, the user can start the application by a shortcut or by voice command with the key words "Hi Lady Laura". When the application opens, an agent named Lady Laura initiates the conversation by guiding the user through the flow implemented in Dialogflow and presented in the online document ${ }^{1}$.

We highlight that the application can be used entirely by voice commands, without at any moment the user has to hold the device in his hands.

Lady Laura is the name of one of several agents implemented for our platform.Control and forwarding for each agent is done programmatically via android code and the agent access key provided in Dialogflow. For purposes of testing and validation of the proposal we used only two of our agents in the technology prototype, Lady Laura and Ana Maria, however, our architecture was elaborated comprehensively so that the system supports the subsequent addition of innumerous agents in the tool from Google.

The scenario implemented was strategically planned to test the interaction between the older adult and the agent over different contexts, a context involving an exchange of personal information between the older adult and an agent and thus creating a bond between them, a context of interruption, in which an agent interrupts the dialogue established between the researcher and the older adult and a context in which the older adult waits for a recipe provided by an agent specialized in cooking.

The scenario implemented was based on the work of Portet et al. [8] and elaborated in order to analyze the behavior of the user before the agent from different angles. We wanted to analyze the reaction of the older adult when interrupted by the agent during a conversation with another person, would they see that interruption with good eyes? Regarding the part of the scenario that involves waiting for an information, would they either accept this waiting time or end the use of the application? Such questions and others in the same context were loaded to a user test with the older adult and the application as central elements of analysis.

\footnotetext{
${ }^{1}$ https://drive.google.com/file/d/1r2KLHy7W10XSVRYBKeCOGaYg40dEkf6R/view? usp=sharing
}

\section{METHODOLOGY}

This work is an exploratory study aimed to understand how Brazilian lower middle class older adult perceives first hand conversational agents when introduced to them in their households. Our protocol mimics the introduction of Guardian to the older adults in their homes by our research team. We introduce the technology and its core features and let them interact.

For this initial study, we had the following recruiting criteria: 1) Older than 60; 2) Had no need for caregivers; 3) Could not afford caregivers and 4) Were willing to let our research team into their homes. Once in their homes, research team read the study protocol to the subjects and collected their signatures on inform consent. Eight individuals aging between 61 and 70 helped us in this study. Table 1 summarizes the main characteristics of the participants.

Table 1: Main characteristics of the participants of the evaluation with the user

\begin{tabular}{|c|c|}
\hline \multicolumn{2}{|r|}{ GENERAL CHARACTERISTICS } \\
\hline Participant 1 & $\begin{array}{l}\text { Female, widowed, with completed high school } \\
\text { and experience of more than } 4 \text { years using } \\
\text { mobile devices. Occupation: retired nursing } \\
\text { technician. Age: } 64 \text { years. Lives with another } \\
\text { person at home. }\end{array}$ \\
\hline Participant 2 & $\begin{array}{l}\text { Female, divorced, with incomplete primary } \\
\text { education and no experience with mobile } \\
\text { devices. Occupation: retired housewife. Age: } 67 \\
\text { years. Lives with } 7 \text { other people at home. }\end{array}$ \\
\hline Participant 3 & $\begin{array}{l}\text { Male, married, with incomplete primary } \\
\text { education and no experience with mobile } \\
\text { devices. Occupation: retired farmer. Age: } 64 \\
\text { years. Lives with } 1 \text { other person at home. }\end{array}$ \\
\hline Participant 4 & $\begin{array}{l}\text { Female, widowed, with incomplete primary } \\
\text { education and no experience with the use of } \\
\text { mobile devices. Occupation: retired merchant. } \\
\text { Age: } 62 \text { years. Lives with } 1 \text { other person at home. }\end{array}$ \\
\hline Participant 5 & $\begin{array}{l}\text { Female, widowed, with incomplete primary } \\
\text { education and no experience with mobile } \\
\text { devices. Occupation: retired housewife. Age: } 70 \\
\text { years. Lives with } 2 \text { other people at home. }\end{array}$ \\
\hline Participant 6 & $\begin{array}{c}\text { Female, married, with completed high school } \\
\text { and } 3 \text { to } 4 \text { years of experience using mobile } \\
\text { devices. Occupation: retired housewife. Age: } 61 \\
\text { years. Lives with } 1 \text { other person at } \\
\text { home. }\end{array}$ \\
\hline Participant 7 & $\begin{array}{l}\text { Female, widowed, with incomplete primary } \\
\text { education and no experience with the use of } \\
\text { mobile devices. Occupation: retired farmer. } \\
\text { Age: } 63 \text { years. Lives with } 2 \text { other people at home. }\end{array}$ \\
\hline Participant 8 & $\begin{array}{l}\text { Female, widowed, with no schooling and no } \\
\text { experience with mobile devices. Occupation: } \\
\text { retired housewife. Age: } 66 \text { years. Lives with } 6 \\
\text { other people at home. }\end{array}$ \\
\hline
\end{tabular}

After the socio-technological profile questionnaire completion, we set up the our equipment: a smartphone Xiaomi model Mi Max 2 , with the android 7.1.1 operating system and $4 \mathrm{G}$ connection. The 


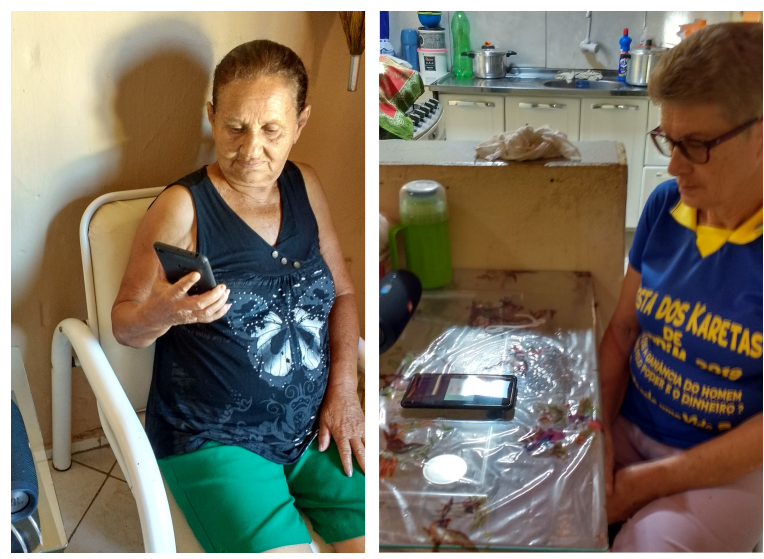

Figure 2: Evaluation with users

internet connection is necessary since Guardian uses Google Technology to process conversation. Associated to the smartphone, a JBL Charge 3 bluetooth sound box with microphone was used. Both audio input and output was made through JBL, that is increase signal salience and lower the likelihood of misunderstandings. Despite neutralizing the hyperpersonality indicated by Pellanda [18], a single device being used by all the participants had the objective of avoiding that different perceptions had as cause the use of equipment with different operating systems, screen size and processing capacity. In Figure 2, we illustrate the evaluation sections with the users.

Such equipment configuration was also designed to simulate tools like Amazon's Alexa and Google Home and provide similar set of affordances, but with greater freedom for users who can use the application with or without the sound box and still anywhere they want, such as at home or on the street. The devices also flexibilize and provide greater freedom during the programming, since the technologies used are free.

All subjects observed curiously the easy Guardian setup. All data collection were videotaped with the camera aimed at the participant's face. Such setting also captures all audio produced in the trials. With all relevant elements of the scenario captured, the research team has all it is needed to perform a situated analysis, as proposed by Suchman [19]. All ambient stimuli, artifacts and subjects reaction to them are assessed in tandem to help the research team to make sense of what is truly happening in a deeper and more complete way.

The interaction begins with the main agent of the Guardian (Lady Laura) introducing herself. "Hello my name is... Your happiness and well being are sole motivators. I'd like to know you better... What is your name?"... "Tell me more about you, what is your year of birth?". Upon the answer, Lady Laura invokes the agent of horoscope to briefly chat about the this subject. The idea behind it is to entertain the user and always give something back to his/hers answers.

After that, Lady Laura asks to the user if he/she is interested in learning a healthy little recipe. Upon an affirmative answer, Laura invokes a cooking agent, "wait a minute that I will call a friend, Ana Maria, she knows everything about cooking". Ana Maria does not start conversation immediately upon invocation. A delay was put on purpose. We wanted to analyze how the users would react to the interruption of an established conversation between the researchers and them when the delay ended and Ana Maria appeared. Interruption is when the agent starts the interaction automatically. This should be a key feature for an agent built with this purpose. We want to get involved, motivate the older adult with depression because of the lack of interaction with real people, which is one of the underlying causes of the disease among this group. Then, during the wait for Ana Maria to return with the recipe, a member of our team talks to the user and distracts him/her. We want to capture subject's reaction to a machine calling up the him/her. After a few minutes Ana Maria enters the chat, introduces "herself" and provide her recipe. Then Laura takes up the conversation and ends this first encounter asking the subject for his/her friendship, "can we be friends?".

Further details of such interaction are provided in the qualitative assessment section. At the end of the test section, we applied the SUS questionnaire to investigate the level of usability of the system, such results are presented in the quantitative evaluation section.

\section{DISCUSSION AND RESULTS}

In the following sections we briefly discuss the findings of our experiment by dividing the results of quantitative and qualitative evaluations.

\subsection{QUANTITATIVE EVALUATION}

The SUS is a questionnaire created by John Brooke in 1986, and can be used to evaluate any type of interface. With an average of 68 points, the SUS presents excellent yield and consistency of results for tests with relatively small sample sizes. According to Tullis (2004) with a number of 8 participants, it is already possible to identify preferences and problems through this system with $80 \%$ accuracy. After the use of the prototype by the users the SUS was answered by each participant of the test. In Table 2, we show the answers of the users by question.

In the first question the users who strongly disagreed justified it by saying they had no interest in using a smartphone for functions other than phone calls. Those who responded positively justified that they loved the idea of having a embedded friend on a mobile device. In the second question most found the system very simple to use due to voice interactions. One user remained neutral for having considered this form of interaction a little strange.

In the third question one user disagreed and another one remained neutral because they have strange the interactions by voice. The others found the system simple and intuitive to use. In the fourth question the answers were varied, most of the users informed that they would need help because the system was very different from the others that they were accustomed to use. But three users found the system intuitive enough that they didn't need any help. A user remained neutral because he was not sure what to answer.

In the fifth question there was a general agreement that the functions of the system were very well integrated. In the sixth question there was general agreement that the functions of the system were very well consistent. In the seventh question two 
Table 2: Answers of the SUS by question

\begin{tabular}{|c|c|c|c|c|c|}
\hline Question & $\begin{array}{l}\text { Strongly } \\
\text { Disagree }\end{array}$ & Disagree & Neutral & Agree & $\begin{array}{l}\text { Strongly } \\
\text { Agree }\end{array}$ \\
\hline $\begin{array}{l}\text { 1. I think that I } \\
\text { would like to use } \\
\text { this system } \\
\text { frequently. }\end{array}$ & 2 & 0 & 0 & 0 & 6 \\
\hline $\begin{array}{l}\text { 2. I found this } \\
\text { system } \\
\text { unnecessarily } \\
\text { complex. }\end{array}$ & 7 & 0 & 1 & 0 & 0 \\
\hline $\begin{array}{l}\text { 3. I thought this } \\
\text { system was easy } \\
\text { to use. }\end{array}$ & 1 & 0 & 1 & 0 & 6 \\
\hline $\begin{array}{l}\text { 4. I think that I } \\
\text { would need } \\
\text { assistance to be } \\
\text { able to use this } \\
\text { system. }\end{array}$ & 2 & 1 & 1 & 0 & 4 \\
\hline $\begin{array}{l}\text { 5. I found the } \\
\text { various functions } \\
\text { in this system } \\
\text { were well } \\
\text { integrated. }\end{array}$ & 0 & 0 & 0 & 0 & 8 \\
\hline $\begin{array}{l}\text { 6. I thought there } \\
\text { was too much } \\
\text { inconsistency in } \\
\text { this system. }\end{array}$ & 8 & 0 & 0 & 0 & 0 \\
\hline $\begin{array}{l}\text { 7. I would imagine } \\
\text { that most people } \\
\text { would learn to } \\
\text { use this system } \\
\text { very quickly. }\end{array}$ & 0 & 0 & 2 & 1 & 5 \\
\hline $\begin{array}{l}\text { 8. I found this } \\
\text { system very } \\
\text { cumbersome/aw } \\
\text { kward to use. }\end{array}$ & 6 & 1 & 0 & 1 & 0 \\
\hline $\begin{array}{l}\text { 9. I felt very } \\
\text { confident using } \\
\text { this system. }\end{array}$ & 1 & 1 & 1 & 0 & 5 \\
\hline $\begin{array}{l}\text { 10. I needed to learn } \\
\text { several things } \\
\text { before I could } \\
\text { use the system. }\end{array}$ & 7 & 1 & 0 & 0 & 0 \\
\hline
\end{tabular}

users remained neutral considering that this affirmation would vary from person to person. The rest agreed due to, according to them, the system guide the user during use.

In the eighth question most users strongly disagreed with such an assertion because they considered the system very simple. The user who agreed justified his answer for the lack of habit with an application by voice commands. In the ninth question most users agreed with the affirmation because that they felt guided during the interaction. Those who disagreed said they felt insecure using a voice application for the first time. One user remained neutral due to the uncertainty of the response. And finally, in the tenth question, the disagreement with such a statement was general. Users attributed this to the time taken to learn the basic features of the system, which was in minutes.

After collecting the results we performed the necessary calculations and obtained a final score of 83.125. During the test we also obtained optimistic feedbacks from users. These feedbacks obtained through interviews with the researchers and relevant information obtained in the participant profile questionnaire are reported in the qualitative evaluation section described below.

\subsection{QUALITATIVE EVALUATION}

The scenario can be divided into three main parts, a part of information exchange, a part referring to waiting for a culinary recipe and a part referring to the interruption of the system. All three provided us with valuable feedbacks from users.

Most users loved talk with the agent, the change of personal information, so that the agent knew his user better, was well accepted by the eight interviewees. One of them said: "I've never seen anything like it, I liked the fact that Lady Laura wanted to know my name". But for some, the waiting and interruption weren't well accepted.

In the part of the interruption one of the users was annoyed to have his dialogue with the researcher ceased by the agent. "I don't like it when I'm interrupted during a conversation, I think that's a lack of respect," said one of the users. At the moment the user's speech was interrupted, he would talk to the researcher about his life and his daily routine. The other participants weren't offended by the interruption, some even found it funny and interesting. "I was surprised when Ana Maria comes up with a cooking recipe, she already speaks the recipe, I found it very interesting," said another user.

Concerning the wait for a culinary recipe two of the eight users were bored while waiting for the exchange of agents and the recipe provided after this. "She took a long time to bring the recipe, I was without patience," said one of them. The researchers perceived a certain impatience in these two users and their desire to finish the experiment briefly. Such impatience can be perceived as anxiety, which is not a good feeling and should be avoided in the design of any interaction. We posit that in real long term use such feeling should disappear, but that remains to be seen. In the other users the main reactions noted were happiness and surprise, they loved the idea of one agent calling another and didn't care at all about waiting for it. "I loved this agent-swap thing and the revenue they gave me," another user said. An important point to mention was that all users reported that they had never used an entirely voicebased application like ours, which made them curious about our technology.

In Table 3, we illustrate the experiment with two users and their reactions in the three parts of the scenario mentioned above.

One point worth mentioning is that six of the eight older adults interviewed didn't have a smartphone, just a simple cell phone for calls or no mobile device, but still managed to use the Guardian. Such information is also relevant because it shows not only the affinity with the technology but also their economic/cultural status. They don't have smartphones either because they cannot afford (probably the main reason) or because they could not perceive the utility of having one in their daily lives.

After the experiment the researchers asked if they would be interested in owning a smartphone with the technology under study. Six of the eight users said yes, they would have an interest in the technology. The other two reported that they wouldn't be interested in using the cell phone for other functions than telephone 
Table 3: User reactions during the three parts of the scenario

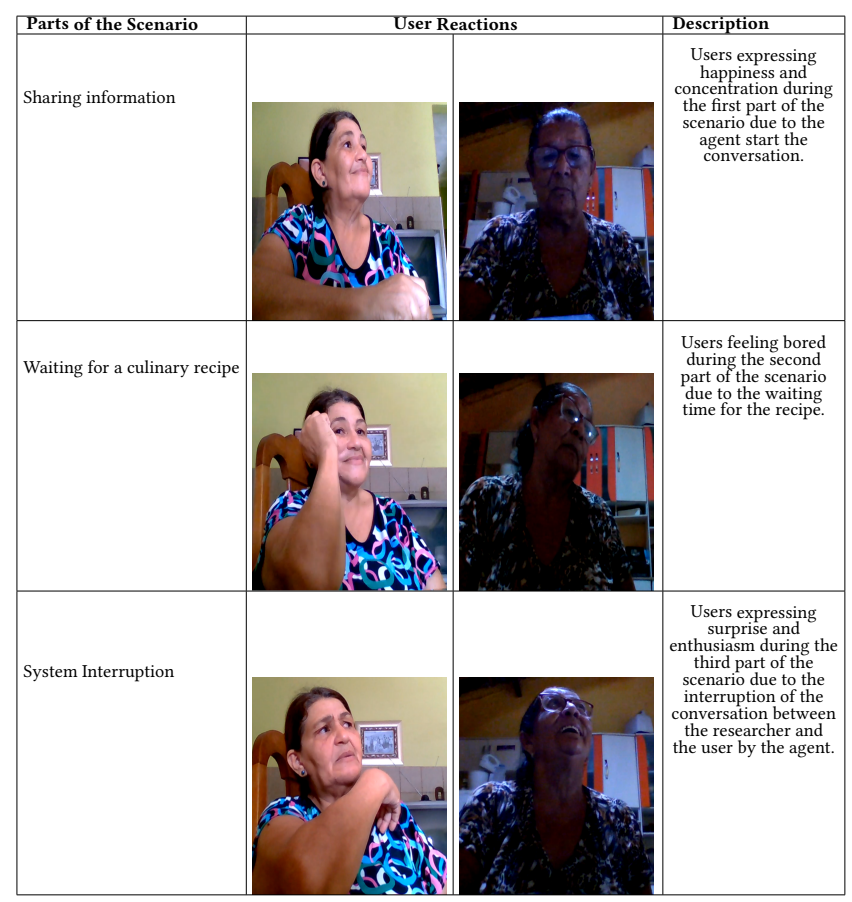

calls and that a simple device already supplied the need for them. Another highlight was the request for friendship by Lady Laura at the end of her conversation flow. All eight users answered yes, they would be interested in creating a bond of friendship with the agent. This fact strengthens users acceptance of technology.

Another highlight was the configuration of devices, to simulate technologies such as Alexa and Google Assistant, which consisted of a smartphone with android operating system and a bluetooth sound box with microphone. For one of the eight users this setup was essential since he suffered from severe hearing impairments. It was touching to see his satisfaction using the Guardian's prototype without losing the application information by sound and text. This user even asked the researchers if he could make use of a bluetooth sound box for other functions of the smartphone, such as telephone calls. He reported that he didn't have a smartphone because he couldn't hear any sound coming from the device, but using the Guardian's prototype with the sound box, he had no problem to listening the informations. The researchers guided how the participant could use a sound box for other functions of the smartphone and he was very grateful for that.

We also highlight the main reason for the acceptance of technology, according to the older adult, the companionship. Six of the eight seniors reported that they would love to own a smartphone with a embed friend, a full-time fellow, who would always be available to talk and pass the time. The other two participants were interested in having a full-time companion, but not with the idea of this companion being a conversational assistant on a mobile device.

More than functionalities the older adult want a partner, someone always available to him, since they often feel lonely and depressed at home. Some users have reported that they do or already did some treatment for depression.

It has been noticed yet, through the responses of the sociotechnological profile questionnaire and the researchers' inquiries, that almost all participants reported that they love to listen to radio every day and that a functionality involving radio programs in the technology prototype would make the same to have a much greater acceptance by them.

\section{LIMITATIONS OF THE STUDY}

It should be emphasized that the study present biases that reduce the generality of the findings. The experiment was carried out with people from only one area of Brazil, and the sample is quite small. Having said that, it also should be noticed the subjects, arguably, represent the worst case scenario since most of them do not even own a smartphone.

Furthermore, the study was mainly qualitative, investigating the main objections of users of the system being tested. Thus, we believe that at this stage of development, a sample of larger size wouldn't have greatly modified the evaluation of the technology.

\section{CONCLUSION AND FUTURE WORK}

In the Introduction section we raised several research questions that this study tries to answer. We now revisit them. The first one was: 1) Are personal assistants like Amazon's Alexa or Google's assistant offer any help for third world country seniors? We posit that the answer seems to be Yes. Despite the limitations of this study, one can appreciate the early signs of acceptance of the technology among this population who are almost out of the reach of direct human computer interaction. As conversation is a more natural way of interaction, the older adult were able to talk to the machine and get their intentions understood and had fun with it.

The second and third question were: How does such population receive and interact with such technology and Which culture related issues might arise from the introduction of the technology in their daily lives? We will try to answer both of them together. Subjects were both surprised and annoyed by this new talking entity in their living rooms. Surprised because most them had never talked to a computer and could not realize that they could hear and talk so clearly. The idea of having this electronic friend never passed through their minds. Annoyed, some of them, because they felt that this new friend does interrupt somebody else's conversation, which is seen as not been polite. We should address this issue in future versions of the system. Lady Laura should ask permission to talk, first, just like a child does in the presence of adults, in Brazil. Interestingly, similarly to a child or an adolescent the technology needs to know how it fits in the society.

Question four: Which possible positive impacts can be fore- seen with the use of conversational assistants? We actually think that with more studies these technologies will be able to blend into people's lives. Culturally speaking, people of this age don't like not knowing what to do. A careful choice of words and interaction scenarios might the way to persuade them to do what is relevant for healthy aging.

Fifth and final question was: Which design guidelines can be drawn from this exploratory study? We argue that out smalltalk 
approach seems to be a way to gain people's trust. People have pets, they talk to them and somehow receive feedback. The horoscope agent and the recipe guru, both agents, were well received as they create an illusion of several different people doing things for them. Maybe in the future we should create a more sophisticated story line linking the agents, like in some sort of trama, to promote entertainment. Potent speakers and sensible microphones were also proven to be of great help to smooth the interaction with this population.

Long term engagement is still an open question. Will the Guardian technology the able to deliver relevant habit building/transforming strategies. That require long term use. Follow up studies should include the use of the technology with a group of older adults enrolled in habit changing program. The Guardian should be more social linking group participants, motivating them collectively. Calling they to engage in real world social activities, maybe even accompanying them in their social gatherings.

\section{ACKNOWLEDGMENTS}

\section{REFERENCES}

[1] IBGE Instituto Brasileiro de Geografia e Estatística. Projeção da população do brasil e das unidades da federação, 2018. http://www.ibge.gov.br/apps/populacao/ projecao/.

[2] Markus Vinicius Nahas. Atividade fisica, saúde e qualidade de vida: conceitos e sugestões para um estilo de vida ativo. Midiograf, 2001.

[3] Sandra Renata Pinatti de Moraes and Luis Sidônio Teixeira da Silva. An evaluation of the burden of alzheimer patients on family caregivers. Cadernos de Saúde Pública, 25:1807-1815, 2009.

[4] Déborah Cristina Oliveira, Maria José D’Elboux, et al. Estudos nacionais sobre cuidadores familiares de idosos: revisão integrativa. Revista Brasileira de Enfermagem, 2012.

[5] Talita Cristina Barbosa Rezende, Arlete Maria Valente Coimbra, Lilian Tereza Lavras Costallat, and Ibsen Bellini Coimbra. Factors of high impacts on the life of caregivers of disabled elderly. Archives of gerontology and geriatrics, 51(1):76-80, 2010

[6] Michael Gordon. Community care for the elderly: is it really better? CMAJ Canadian Medical Association fournal, 148(3):393, 1993.

[7] Alisha Pradhan. Exploring the accessibility of home-based, voice-controlled intelligent personal assistants. $\mathrm{PhD}$ thesis, 2018.

[8] François Portet, Michel Vacher, Caroline Golanski, Camille Roux, and Brigitte Meillon. Design and evaluation of a smart home voice interface for the elderly: acceptability and objection aspects. Personal and Ubiquitous Computing, 17(1): 127-144, 2013.

[9] Arsénio Reis, Dennis Paulino, Hugo Paredes, and João Barroso. Using intelligent personal assistants to strengthen the elderlies' social bonds. In International Conference on Universal Access in Human-Computer Interaction, pages 593-602. Springer, 2017.

[10] Arsénio Reis, Isabel Barroso, Maria João Monteiro, Salik Khanal, Vitor Rodrigues, Vitor Filipe, Hugo Paredes, and João Barroso. Designing autonomous systems interactions with elderly people. In International Conference on Universal Access in Human-Computer Interaction, pages 603-611. Springer, 2017.

[11] S. Noh, J. Han, J. Jo, and A. Choi. Virtual companion based mobile user interface: An intelligent and simplified mobile user interface for the elderly users. In 2017 International Symposium on Ubiquitous Virtual Reality (ISUVR), pages 8-9, June 2017. doi: 10.1109/ISUVR.2017.10.

[12] A. Cheng, V. Raghavaraju, J. Kanugo, Y. P. Handrianto, and Y. Shang. Development and evaluation of a healthy coping voice interface application using the google home for elderly patients with type 2 diabetes. In 2018 15th IEEE Annual Consumer Communications Networking Conference (CCNC), pages 1-5, Jan 2018. doi: 10 1109/CCNC.2018.8319283.

[13] Mladen Milošević, Michael T Shrove, and Emil Jovanov. Applications of smartphones for ubiquitous health monitoring and wellbeing management. FITAJournal of Information Technology and Aplications, 1(1), 2011.

[14] Pavel Slavík, Vladislav Nemec, and Adam Sporka. Speech based user interface for users with special needs. volume 3658, pages 45-55, 09 2005. doi: 10.1007/ 11551874_6.

[15] Michel Kramer Borges de Macedo et al. Recomendações de acessibilidade e usabilidade para ambientes virtuais de aprendizagem voltados para o usuário idoso. 2009.
[16] DialogFlow. Build natural and rich conversational experiences., 2019. https: //dialogflow.com.

[17] Herrera R. R. Rico M. A. Rossell, N. Y. Introducción a la psicogerontología. pirámide. 2004.

[18] Eduardo Campos Pellanda. Comunicação móvel no contexto brasileiro. Comunicação e mobilidade, 11, 2009.

[19] Lucy Suchman. Human-machine reconfigurations: Plans and situated actions. Cambridge University Press, 2007. 